\title{
Upfront boost Gamma Knife "leading-edge" radiosurgery to FLAIR MRI-defined tumor migration pathways in 174 patients with glioblastoma multiforme: a 15-year assessment of a novel therapy
}

\author{
Christopher M. Duma, MD, ${ }^{1,2}$ Brian S. Kim, MD, ${ }^{2,3}$ Peter V. Chen, MD, ${ }^{2,3}$ Marianne E. Plunkett, MS,, \\ Ralph Mackintosh, PhD, ${ }^{2,3}$ Marlon S. Mathews, MD, ${ }^{4}$ Ryan M. Casserly, MD, ${ }^{1}$ \\ Gustavo A. Mendez, MD, ${ }^{1}$ Daniel J. Furman, MS, ${ }^{1}$ Garrett Smith, BS, ${ }^{1}$ Nathan Oh, DO, ${ }^{1,5}$ \\ Chad A. Caraway, BS, ${ }^{1}$ Ami R. Sanathara, BA, ${ }^{1}$ Robert O. Dillman, MD, ${ }^{2}$ Azzurra-Sky Riley, ${ }^{1}$ \\ David Weiland, BS, Lian Stemler, ${ }^{1}$ Ruslana Cannell, BS, ${ }^{2}$ Daniela Alexandru Abrams, MD, ${ }^{4}$ \\ Alexa Smith, MD, ${ }^{4}$ Christopher M. Owen, MD, ${ }^{4}$ Burton Eisenberg, MD, ${ }^{2}$ and \\ Michael Brant-Zawadzki, MD ${ }^{1,2}$
} ${ }^{1}$ Neurosciences Institute, ${ }^{2}$ Cancer Center, and ${ }^{3}$ Department of Radiation Oncology, Hoag Memorial Hospital Presbyterian,
Newport Beach; ${ }^{4}$ Department of Neurosurgery, University of California, Irvine, Orange; and ${ }^{5}$ Department of Neurosurgery, Loma
Linda University Health, Loma Linda, California

\begin{abstract}
OBJECTIVE Glioblastoma multiforme (GBM) is composed of cells that migrate through the brain along predictable white matter pathways. Targeting white matter pathways adjacent to, and leading away from, the original contrast-enhancing tumor site (termed leading-edge radiosurgery [LERS]) with single-fraction stereotactic radiosurgery as a boost to standard therapy could limit the spread of glioma cells and improve clinical outcomes.
\end{abstract}

METHODS Between December 2000 and May 2016, after an initial diagnosis of GBM and prior to or during standard radiation therapy and carmustine or temozolomide chemotherapy, 174 patients treated with radiosurgery to the leading edge (LE) of tumor cell migration were reviewed. The LE was defined as a region outside the contrast-enhancing tumor nidus, defined by FLAIR MRI. The median age of patients was 59 years (range 22-87 years). Patients underwent LERS a median of 18 days from original diagnosis. The median target volume of $48.5 \mathrm{~cm}^{3}$ (range $2.5-220.0 \mathrm{~cm}^{3}$ ) of LE tissue was targeted using a median dose of 8 Gy (range 6-14 Gy) at the $50 \%$ isodose line.

RESULTS The median overall survival was 23 months (mean 43 months) from diagnosis. The 2-, 3-, 5-, 7-, and 10-year actual overall survival rates after LERS were $39 \%, 26 \%, 16 \%, 10 \%$, and $4 \%$, respectively. Nine percent of patients developed treatment-related imaging-documented changes due to LERS. Nineteen percent of patients were hospitalized for management of edema, $22 \%$ for resection of a tumor cyst or new tumor bulk, and $2 \%$ for shunting to treat hydrocephalus throughout the course of their disease. Of the patients still alive, Karnofsky Performance Scale scores remained stable in $90 \%$ of patients and decreased by $1-3$ grades in $10 \%$ due to symptomatic treatment-related imaging changes.

CONCLUSIONS LERS is a safe and effective upfront adjunctive therapy for patients with newly diagnosed GBM. Limitations of this study include a single-center experience and single-institution determination of the LE tumor target. Use of a leading-edge calculation algorithm will be described to achieve a consistent approach to defining the LE target for general use. A multicenter trial will further elucidate its value in the treatment of GBM.

http://thejns.org/doi/abs/10.3171/2016.7.GKS161460

KEY WORDS leading edge; glioblastoma multiforme; Gamma Knife; stereotactic radiosurgery; brain tumor; astrocytoma; migration; FLAIR; fluid-attenuated inversion recovery

ABBREVIATIONS CTV = clinical tumor volume; GBM = glioblastoma multiforme; GTV = gross tumor volume; IFXRT = involved-field radiation therapy; KPS = Karnofsky Performance Scale; LE = leading edge; LERS = leading-edge radiosurgery; TRIC = treatment-related imaging change.

SUBMITTED June 9, 2016. ACCEPTED July 13, 2016.

INCLUDE WHEN CITING DOI: 10.3171/2016.7.GKS161460. 
$\mathrm{W}$ HO Grade IV astrocytoma (glioblastoma multiforme $[\mathrm{GBM}]$ ) is the most common primary malignant brain tumor in adults, with an annual incidence of nearly 3.13 per 100,000 persons..$^{10}$ In 2014, the National Cancer Institute estimated that there were 23,380 newly diagnosed brain or other CNS tumors, with an estimated 14,320 deaths. ${ }^{10}$ GBM accounts for approximately $15 \%$ of all brain tumors and primarily occurs in adults between the ages of 45 and 70 years. ${ }^{10}$ Unfortunately, despite aggressive surgery, radiation therapy, immunotherapy, $28,38,40,41,49,55$ and chemotherapy, the prognosis for this disease remains poor.

Recently, bevacizumab has been relegated to adjuvant therapy for recurrent disease only ${ }^{13}$ and temozolomide has shown static results even with dose escalation..$^{5,14,45} \mathrm{Op}$ tune $\mathrm{TTF}^{11}$ had originally been shown to have only the same efficacy as best medical therapy, but results of a new larger upfront study boast a median survival of up to 20.5 months. Unfortunately, to achieve this, the patient is relegated to wearing a headgear device 18 hours per day for a year.

Local recurrence remains the predominant mode of treatment failure, with $90 \%$ of recurrences located within $2 \mathrm{~cm}$ of the enhancing edge of the original tumor on imaging. ${ }^{18,53}$ Although extent of resection is important, despite improvements in technique such as image-guided surgery and microneurosurgery, local control of GBM cannot be achieved with surgery alone..$^{1,3,6,26,52,56}$ Indeed, Dandy and others noted that even hemispherectomy was not curative. ${ }^{8}$ This should not have been surprising, however, because by the time of diagnosis, tumor cells had already spread from the tumor epicenter.

Image-guided stereotactic biopsies typically confirm infiltrating tumor cells in the edematous region (FLAIR positive) beyond the contrast-enhancing tumor margin as demonstrated on either MR images or CT scans. ${ }^{20}$ Because of this pattern of spread, the benefits of surgery are limited and the morbidity of more extensive resection outweighs any improvement in local control. Thus, a maximal safe resection, followed by temozolomide chemotherapy with concomitant involved-field radiation therapy (IFXRT), remains the current standard of care for surgical management of GBM, despite only a modest increase in median survival of 2.5 months with the addition of temozolomide. ${ }^{45}$

Similarly, in the case of recurrent GBM, results of studies using temozolomide in varying regimens and bevacizumab have been disappointing. ${ }^{7,21,33}$ In a study combining ipilimumab and bevacizumab for new and recurrent GBM, $33 \%$ of patients showed a partial response, $31 \%$ had stable disease, and 38\% had disease progression. The treatment combination was "well tolerated," although the treatment protocol was terminated before completion due to adverse events in $10 \%$ of patients. ${ }^{5}$

The RTOG 93-05 trial, which compared carmustine with or without a radiosurgery boost to the enhancing nidus, showed no difference between the 2 groups. This study demonstrated the futility of targeting only the gadolinium-avid portion of a GBM. This study did not address the fact that tumor cells had already migrated well beyond the study target for radiosurgery. ${ }^{43}$
We have addressed this deficiency of RTOG 93-05 and have defined a new and novel target for radiation dose escalation along migratory white matter pathways adjacent to, and leading away from, the initial, contrast-enhancing site of GBM (as defined by FLAIR MRI and MR spectroscopy). This approach respects that the enhancing volume of GBM is only one component of the tumor burden (Fig. 1). We term this area of spread, as defined by FLAIR positivity distant from the gadolinium avid-enhancing tumor, the "leading edge" (LE), and hypothesize that leadingedge radiosurgery (LERS) will improve local control and survival for patients with newly diagnosed GBM.

\section{Methods}

This is a retrospective analysis of 174 patients with newly diagnosed GBM who were treated with upfront LERS. Permission for the analysis of patient data was obtained from the Western Institutional Review Board for the Protection of Human Subjects and the Coast Independent Review Board. Patients were identified through the record logs of the Hoag Gamma Knife program. Only patients with a histological diagnosis of GBM at original diagnosis were included. All patients underwent craniotomy or stereotactic biopsy for tumor debulking/diagnosis prior to LERS. All patients underwent LERS before or during standard IFXRT and temozolomide chemotherapy (if available, otherwise carmustine). No patient had received any therapies, experimental or conventional, other than IFXRT and standard chemotherapy, nor did patients receive bevacizumab for a treatment-related imaging change (TRIC). Patients with multifocal GBM or gliomatosis cerebri were excluded. Tumor spread across the corpus callosum was not considered exclusionary, nor was tumor in the brainstem, cerebellum, or thalamus/basal ganglia.

Tumors were located evenly between the hemispheres, and LE volumes included the corpus callosum in $20 \%$, the basal ganglia in $7 \%$, and the thalamus in $6 \%$ of tumors (Table 1). The target volume included the volume of tissue with FLAIR abnormality leading away from the contrast-enhancing tumor margin or resection bed along the white matter pathways of spread, as defined by the treating neurosurgeon and radiation oncologist, and encompassed little or no part of the enhancing volume. FLAIR MRI sequences and in some cases MRI-SPECT, using the standard chemical shift multivoxel software supplied by the vendor, was used to design treatment plans that targeted LE tumor migration pathways (Fig. 2).

The dose was prescribed to the $50 \%$ isodose line in all cases, using multiple isocenters to encompass the margin of the LE. The mean target diameter was $20.5 \mathrm{~mm}$ (range $10.9-66.3 \mathrm{~mm}$ ). The median age of patients was 59 years (range 22-87 years). The median recursive partitioning analysis class was 4 (range 3-5). Patients underwent LERS a median of 18 days from the original diagnosis. The median target volume of $48.5 \mathrm{~cm}^{3}$ (range $2.5-220.0$ $\mathrm{cm}^{3}$ ) of LE tissue was targeted using a median dose of 8 Gy (range 6-14 Gy) (Figs. 3 and 4).

The median Karnofsky Performance Scale (KPS) score before LERS was 90. Eight of 174 patients underwent a second or third treatment of LERS, which occurred 

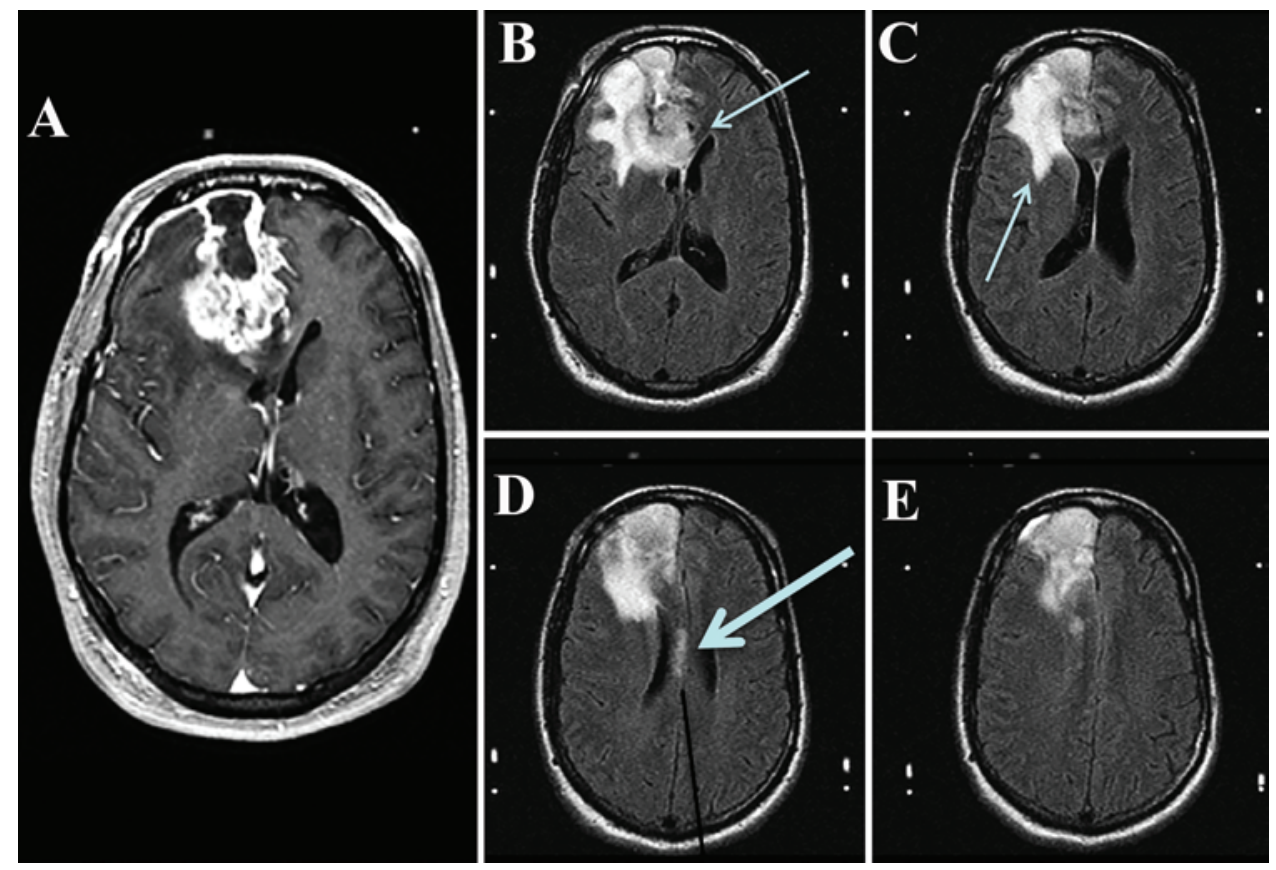

FIG. 1. A: Typical GBM on T1-weighted postcontrast MRI. B-E: "Invisible" tumor migration pathways illuminated on FLAIR sequences, revealing tumor spread in many directions and already distant from tumor epicenter (arrows). These distant areas of spread are probably responsible for our poor control of this disease.

a median of 12 months after their first LERS. The primary end point of this study was overall survival from time of diagnosis.

It was possible to determine IDH-1, MGMT, and EGFRV3 status for patients treated in the most recent 5 years. Thirty-five of 37 (94.5\%), 51.8\%, and $61.1 \%$ of patients tested negative for IDH-1, MGMT methylation, and EGFR overexpression, respectively.

\section{Results}

The median overall survival from diagnosis was 23 months (standard error 0.78 months, mean 43 months). At the time of analysis, 149 patients $(86 \%)$ were dead. The 2-, 3-, 5-, 7-, and 10-year actual overall survival rates using LERS were $39 \%, 26 \%, 16 \%, 10 \%$, and $4 \%$, respectively (Fig. 5). As seen in this graph, compared with the data from studies by Stupp et al., ${ }^{45,46}$ patients who had adjunctive LERS lived longer.

Nine percent of patients developed TRICs, and $4 \%$ required operative intervention for treatment-related symptoms. Six percent of patients had permanent complications attributed to this treatment. The major complication was a symptomatic TRIC (16 of 25 surviving patients), which occurred 6-14 months after LERS (Figs. 6 and 7). One patient experienced a long remission after his first LERS, but after a second LERS for recurrent disease, the TRIC became symptomatic at 1 year. TRICs were typically controlled with a single course of dexamethasone $4 \mathrm{mg}$ four times per day tapering over 16 days, or a second course separated by a week. Seven of the surviving 25 patients required surgical debulking for symptomatic TRICs. Other hospital readmissions included hospitalization for medical management of edema (33 patients) and placement of a shunt for hydrocephalus (4 patients). Resection of a new tumor cyst or new tumor bulk occurred in 38 patients.

It was very difficult to address the morbidity of LERS compared with natural history morbidity of GBM. Of the patients still alive, KPS scores remained stable in $90 \%$ and decreased by 1-3 grades in approximately $10 \%$. The decrease in KPS scores in this subset of patients was temporally related to the TRIC and not actual GBM disease progression. Four of these patients underwent hyperbaric oxygen therapy with minimal clinical improvement. None in this series of upfront-treated patients were treated with bevacizumab for TRICs.

\section{Discussion}

The main difference between GBM and other tumor

TABLE 1. Locations of 174 LE targets

\begin{tabular}{lcc}
\hline Location of LE Target & No. & $\%$ \\
\hline Rt-sided & 89 & 51 \\
\hline Lt-sided & 85 & 49 \\
\hline Frontal & 87 & 50 \\
\hline Temporal & 61 & 35 \\
\hline Parietal & 38 & 22 \\
\hline Occipital & 10 & 6 \\
\hline Basal ganglia & 12 & 7 \\
\hline Thalamus & 10 & 6 \\
\hline Brainstem & 4 & 2 \\
\hline Posterior fossa & 1 & 0.6 \\
\hline Bilat corpus callosum & 34 & 20 \\
\hline
\end{tabular}



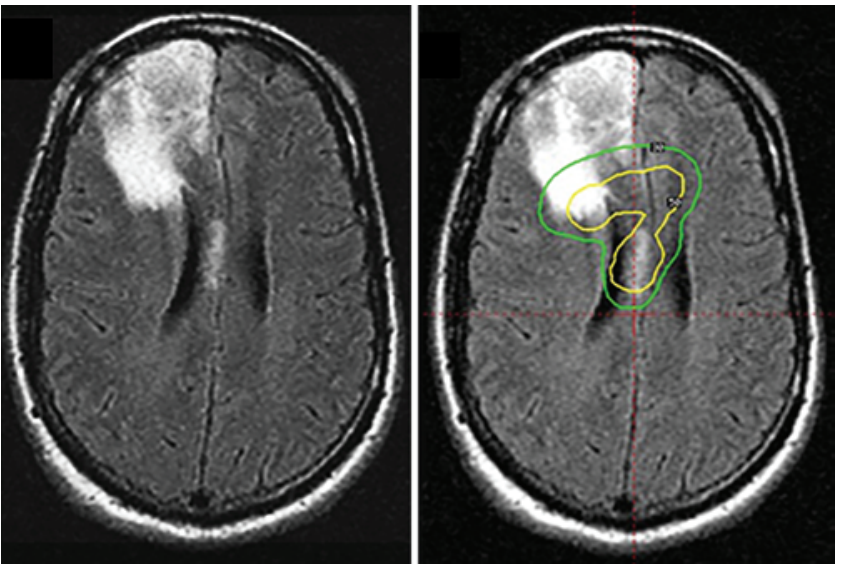

FIG. 2. Left: Distant "invisible" tumor spread into the corpus callosum as revealed on FLAIR sequence seen in Fig. 1. Right: Gamma Knife LERS plan used to arrest migration. A $10-$ Gy dose at the $50 \%$ isodose line was prescribed.

types is that the dividing cells do not grow like a snowball, getting ever larger in a spherical fashion. Instead, their phenotype is to become motile, and their rate of ag- gressive migration may differ between patients. This explains why tumors may appear as multifocal or in the form known as gliomatosis cerebri. It is possible that the IDH-1 variant has a more favorable prognosis because its migration profile is slower.

A key aspect of this mutation to the GBM phenotype is that if the cells are rendered unable to migrate, they die. ${ }^{12,37}$ Thus, we propose that tumor cells within the original enhancing volume of a GBM are usually adequately managed through aggressive resection and IFXRT. After time, however, when they have ultimately outgrown their blood supply, the tumor cells invade locally, seen as palisading histologically. If rendered unable to migrate, perhaps by scarring of the white matter pathways by LERS or direct tumor cell kill by the same, the cells are innately programmed to undergo apoptosis. Furthermore, these apoptotic cells may then serve as an autovaccine to upregulate nearby $\mathrm{T}$ cells toward an abscopal effect..$^{34,44}$

\section{Migration of GBM Cells}

Work with glioma cell lines has shown that diffuse astrocytomas, especially GBM, invade the brain preferentially along white matter fiber tracts. ${ }^{9,12}$ Glial cells express
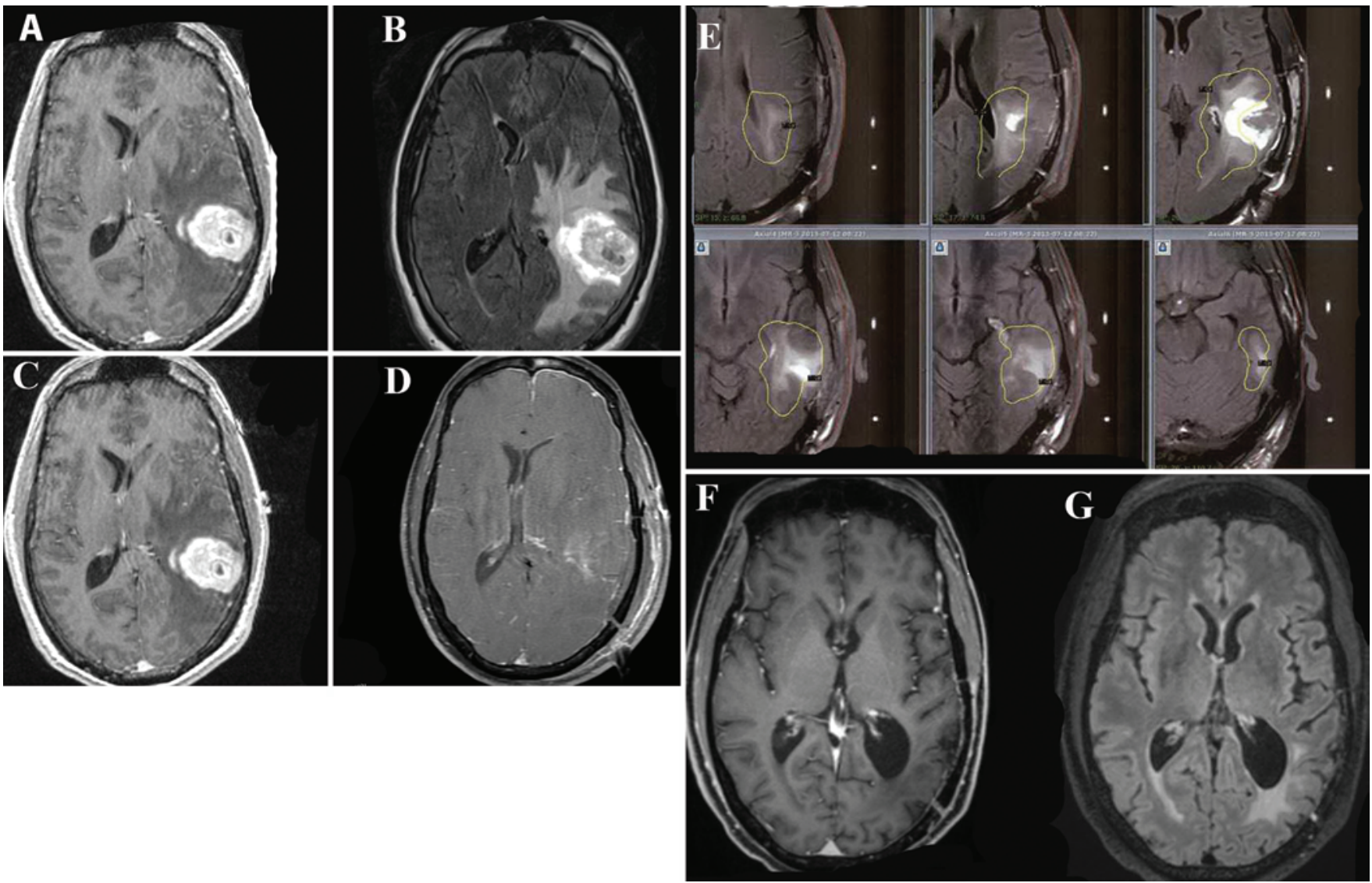

FIG. 3. A: Preoperative T1-weighted Gd-enhanced MR image showing a large GBM in the dominant temporal lobe. The patient's KPS score was 70. B: FLAIR sequence showing multiple LEs of tumor within edema pathways. C and D: Preoperative and postoperative T1-weighted Gd-enhanced MR image showing 99\% tumor resection. E: Gamma Knife LERS plan targeting residual FLAIR abnormality migration pathways. The patient received $11 \mathrm{~Gy}$ at the $50 \%$ isodose line. F: Three-year post-LERS T1-weighted contrast-enhanced MR image. G: Three-year postoperative FLAIR sequence. Images in F and G show no residual tumor and no new edema or mass effect. The patient had a KPS score of 90 (mild receptive dysphasia; markedly improved from before surgery). 

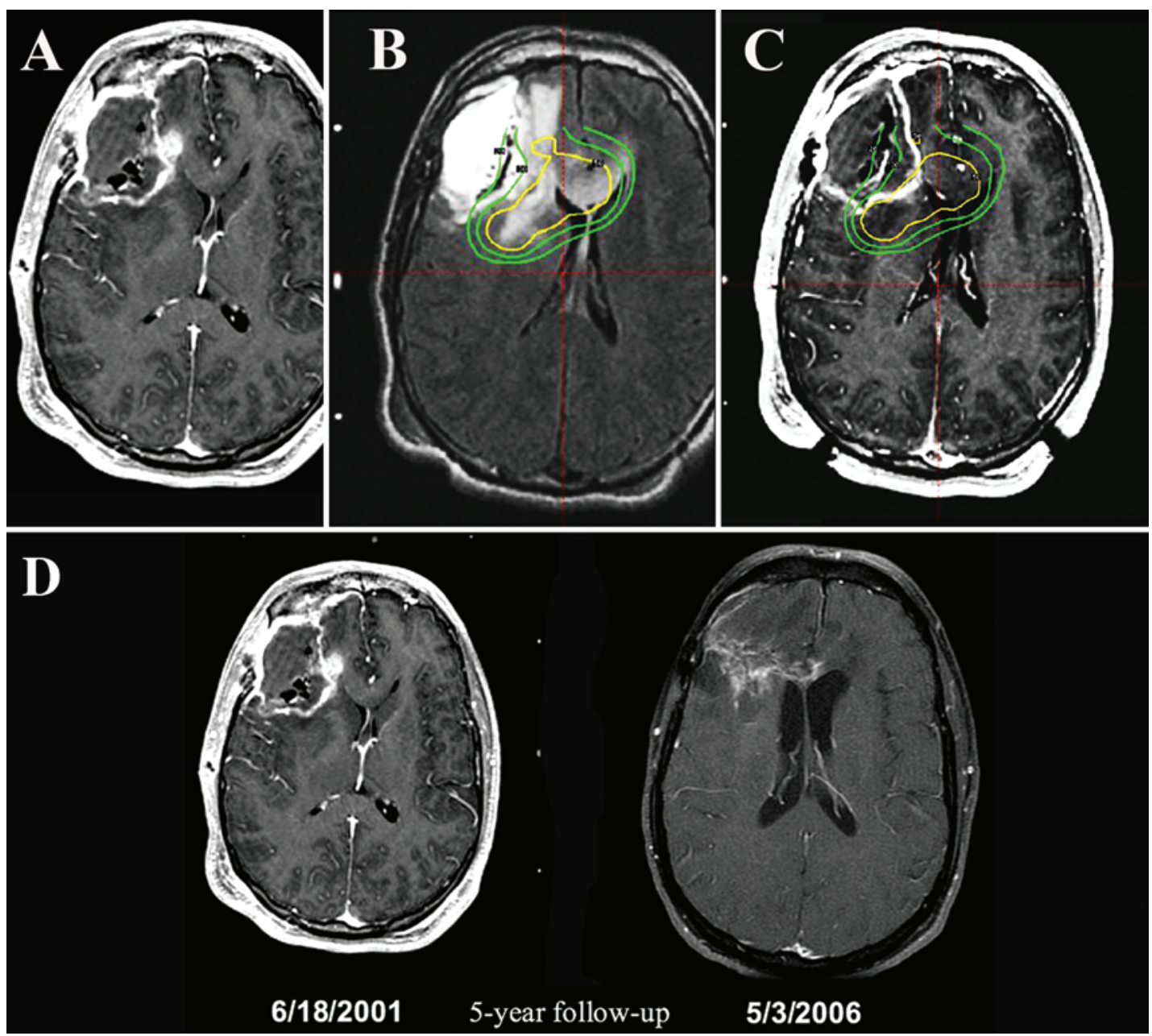

FIG. 4. A: T1-weighted Gd-enhanced MR image obtained the day of Gamma Knife LERS showing postoperative $95 \%$ resection of the tumor bed. B: An LERS FLAIR sequence from the same day, showing "invisible" dramatic migration of tumor across midline and posteriorly down the corona radiata. The LERS plan is overlaid. The patient received $12 \mathrm{~Gy}$ at the $50 \%$ isodose line (yellow). C: The same LERS plan is overlaid on the T1-weighted post-Gd MR image, showing "invisible" tumor spread apparently treating normal brain. D: T1-weighted contrast-enhanced MR images, from the day of LERS and at 5 years later, respectively, showing residual scar tissue. This patient lived 8 years after treatment and ultimately died as a result of GBM progression.

genes that produce membrane type 1 matrix metalloproteinase, ${ }^{2}$ which enables breakdown of the extracellular matrix of white matter, enabling the development of invadopodia and subsequent migration along white matter tracts. Because this property is shared with human fetal brain cells that have been transplanted into the adult brain, it has been hypothesized that the migratory mechanisms of glioma cells may be related to embryonic development and germinal matrix migration. ${ }^{25,32}$

Extracellular matrix remodeling proteins such as membrane type 1 matrix metalloproteinase have been implicated in the mechanism of the migration, because they actively degrade the matrix and create space for the invading glioma. ${ }^{2}$ Upregulated expression of extracellular matrix protein tenascin $\mathrm{C}$, which increases production of contractile machinery and integrin adhesion molecules, has been positively correlated with malignancy and invasiveness. ${ }^{50}$ It has also been shown that if the cells are rendered incapable of migrating, they self-destruct. ${ }^{12,36,37}$ The malignant phenotype must migrate to survive. Spread along white matter pathways generally leads to contralateral spread via the corpus callosum and corona radiata, leading to diffuse, incurable disease.

The pattern of spread of GBM suggests that targeting the original enhancing tumor site will be insufficient when attempting dose escalation. If glial cells have already migrated at the time of treatment, then targeting the source would be ineffective. This is why radiotherapy treatment volumes include tissue beyond the contrast-enhancing margin. Upon retrospective review of MR images in our patients with GBM with recurrence following LERS, we found that recurrence most often occurred along white matter pathways that were spared from the initial targeted treatment zone.

This is exemplified in Figs. 6 and 7, where recurrence and spread occurred 9 years after treatment of the LE of a left temporal GBM outside the LE target, probably down the temporal-occipital fasciculus and corona radiata. Al- 


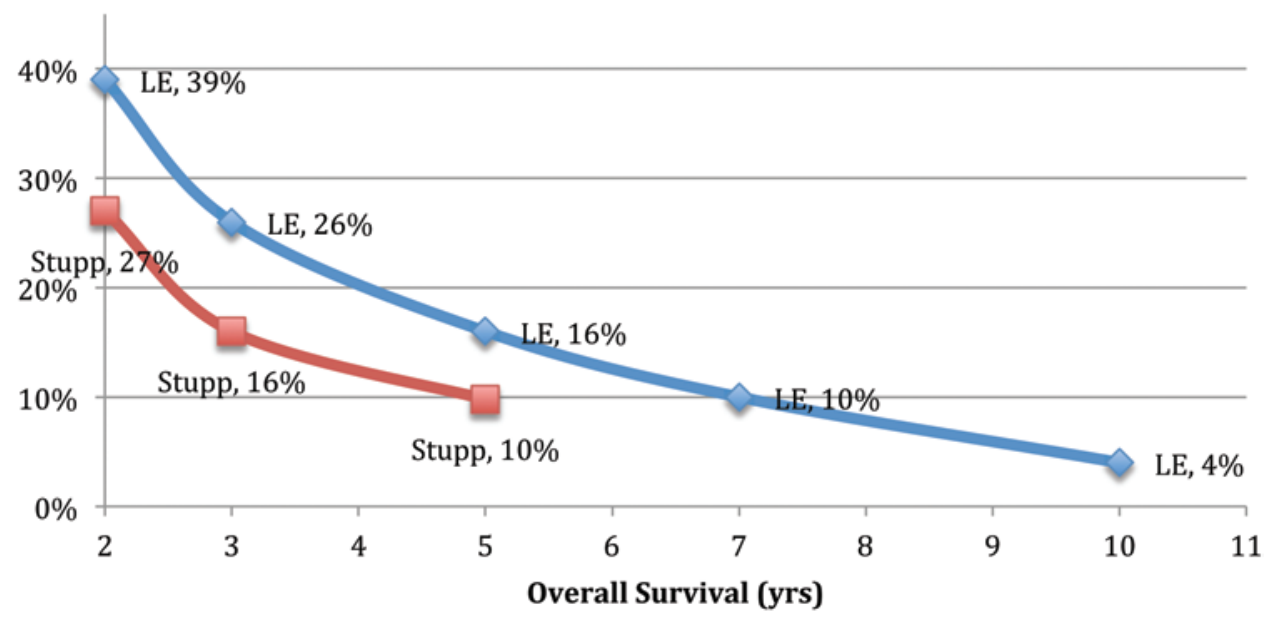

FIG. 5. The percentage of LERS-treated patients alive versus time, compared with data from Stupp et al. ${ }^{45,46}$

though local control in the LE volume was achieved for 9 years in this patient, failure to identify the entire LE probably led to failure of tumor migration control. Thus it is not surprising that trials focused on treating primarily the original enhancing portion of the tumor fail to show a significant survival benefit. ${ }^{43}$ Perhaps RTOG 93-05 failed to show a survival benefit because the radiosurgery focus was on only the original, enhancing tumor.

The aberrant expression of the transcription factor REST (repressor element 1-silencing transcription factor) has been reported in different kinds of tumors. Recent data suggest that REST is a master regulator that maintains GBM cell proliferation and migration, partly through regulating cell cycle by repressing downstream genes. This might represent a potential target for GBM therapy in the future. ${ }^{57}$ However, there are so many factors involved in the migration process ${ }^{19,22,24,25,27,29-31,36,39,42,48,50,51,54,57,58}$ that targeting only one of them is unrealistic. Indeed, in one review article, the 3 characteristics of GBM migration were analyzed: adhesion, motility, and invasion. Between various adhesion molecules (integrins, cadherins, selectins, galectins, the immunoglobulin family, proteoglycans), genes and proteins related to motility (such as paxillin, vinculin, zyxin, tensin), and mutations related to GBM invasion (such as mTOR, PTEN, CAS, and DAP), there are literally hundreds of targetable factors involved in GBM migration. ${ }^{23}$ This is why the effect of a single fraction of LERS may be more efficient-and realistic - in managing this disease.
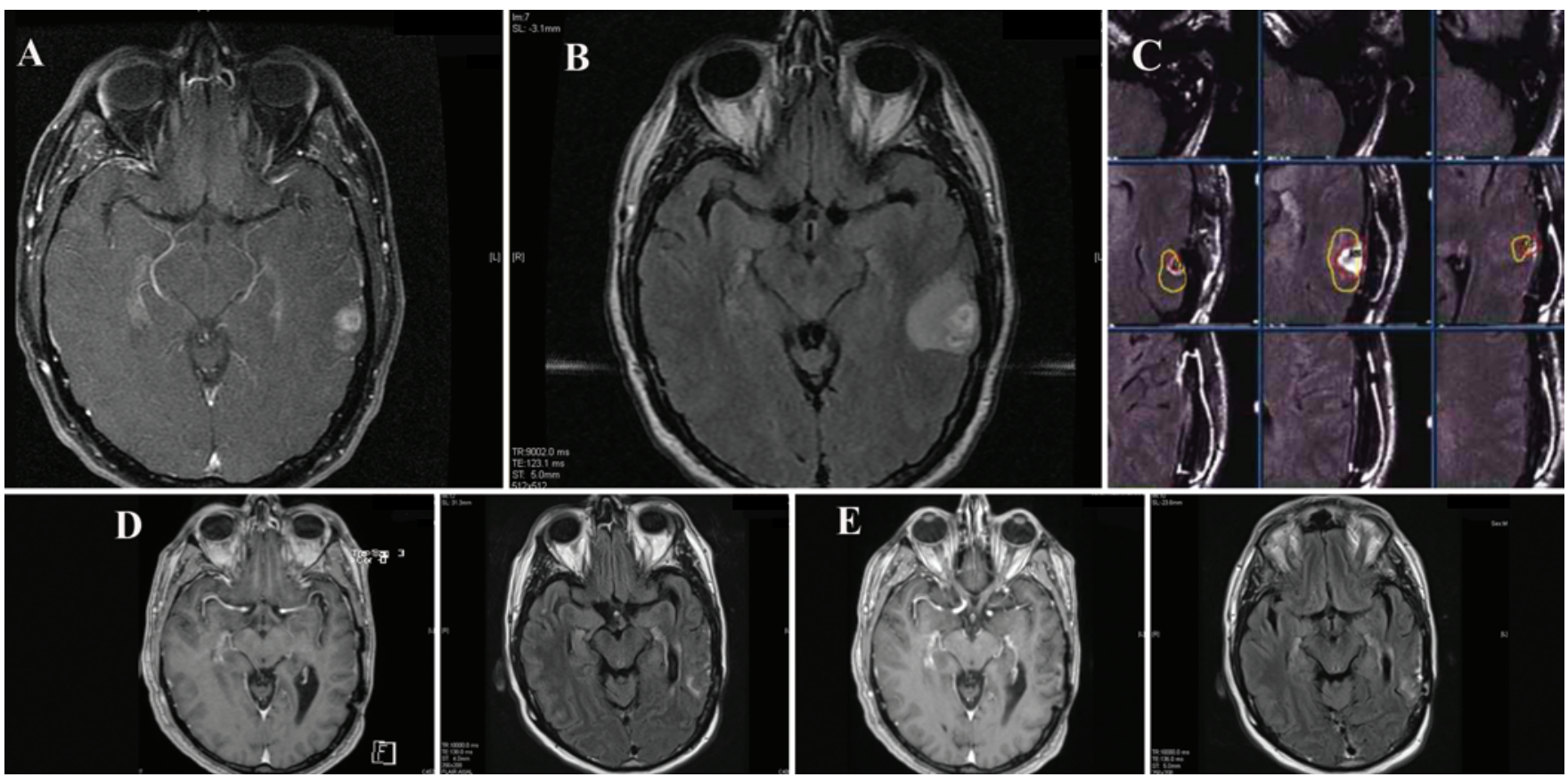

FIG. 6. A-C: Postcontrast image, FLAIR sequence, and Gamma Knife treatment plan of the small-volume LE. D: Four-year follow-up postcontrast and FLAIR sequences, respectively, showing no evidence of tumor recurrence. E: Eight-year follow-up postcontrast and FLAIR sequences, respectively, showing no evidence of tumor recurrence. 

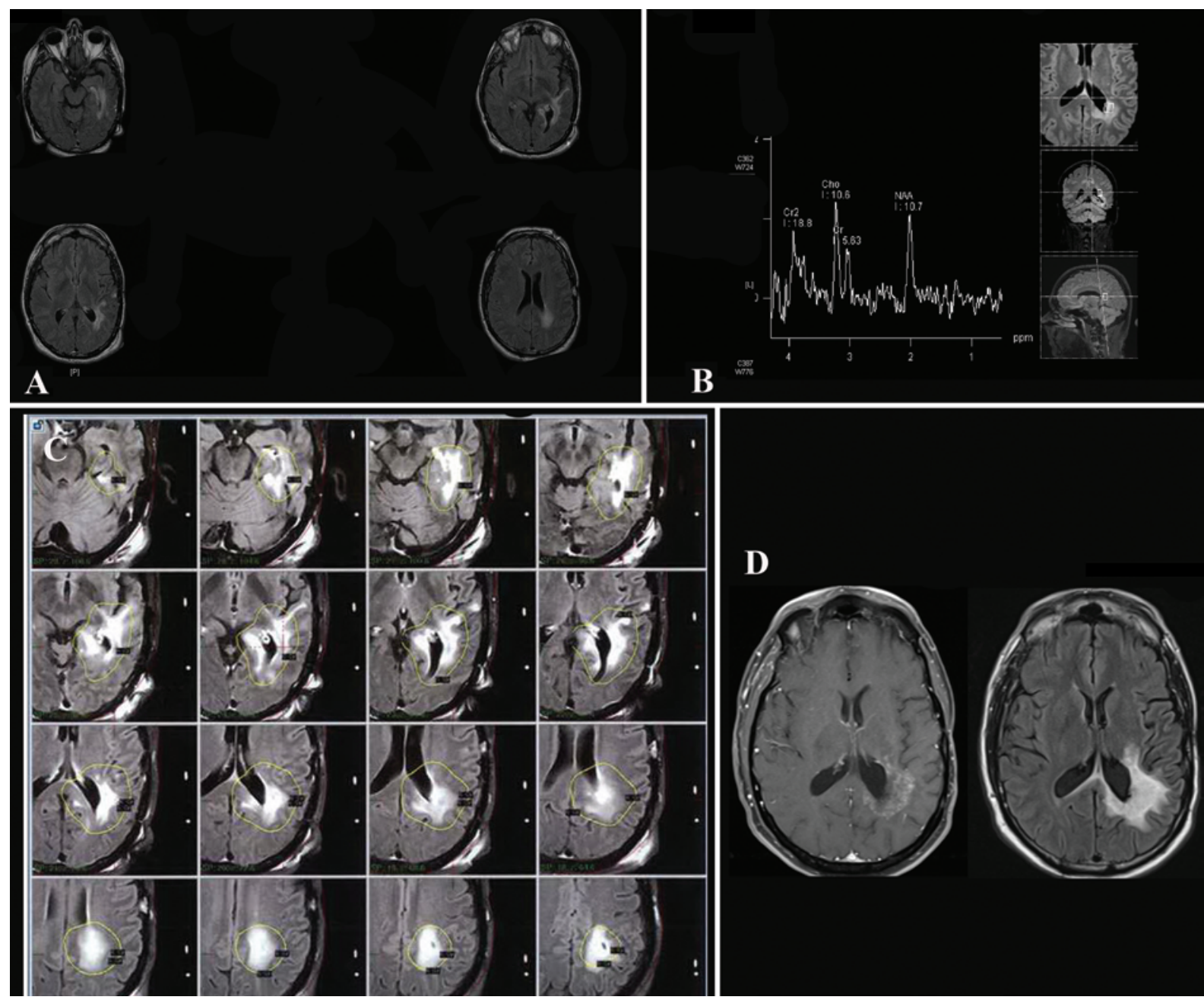

FIG. 7. A: A 9-year post-LERS follow-up MR image of the patient shown in Fig. 6 demonstrating subtle new FLAIR change along white matter pathways leading from the original target/epicenter. B: Confirmation of choline/creatinine ratio consistent with tumor progression, leading to pathological confirmation from stereotactic biopsy. C: Gamma Knife LERS was performed 1 month later for treatment of all abnormal FLAIR regions. D: Ten-year overall follow-up from first LERS and 1-year follow-up from second LERS.

\section{The Effect of Radiation on Migratory Cells}

Additional cellular research suggests that high-dose radiosurgery may be crucial to escalating the dose in the regions of white matter pathways of spread. Videomicroscopic studies have shown that high-dose (>10 Gy) radiation impairs the motility of GBM cells, whereas nonlethal 2-Gy exposures actually increase motility by as much as $20 \%{ }^{17}$ This may explain why dose escalation with radiation therapy in standard fractionation (1.8- to 2-Gy doses) beyond 60 Gy has not proved beneficial. Concordantly, the effect of high-dose radiation on the motility of GBM cells also suggests that stereotactic radiosurgery may be the best modality to escalate dose along white matter pathways of spread.

Based on this, it would be appropriate to consider adding LERS as an adjunct to primary therapy of newly diagnosed GBM, as early as possible after diagnosis. For this reason, the patients in our study were treated with LERS a median of 18 days after diagnosis, minimizing the time allowed for the motile tumor cells to migrate from the epicenter. It is expected that treatments directed at local control of malignant gliomas would improve overall outcomes because $90 \%$ of recurrences in malignant gliomas are located within $2 \mathrm{~cm}$ of the enhancing edge of the original tumor. ${ }^{18,53}$ The problem with this is that $2 \mathrm{~cm}$ is a conservative distance, based on our experience. The tumor shown in Fig. 1 had migrated at least $5 \mathrm{~cm}$ beyond the enhancing epicenter. If the LE of this tumor is neglected, the tumor can progress through the brain unchecked by radiation. The radiation dosage, however, must be considered due to the observed increase in GBM motility at nonlethal exposures of 2 Gy. ${ }^{17}$ The induced local hypoxia has been shown to increase cell migration by $20 \%$, which clearly undermines the local control of the tumor. Indeed, many efforts to intensify local radiation therapy suggest an improvement in outcome with higher doses. Dose escalation with interstitial brachytherapy had been shown to improve local control and survival in selected patients with malignant gliomas, but was ineffective in randomized trials of local delivery. $15,16,20$ 
Another area of interest is the differential radiation of subependymal neural stem cell zones to potentially thwart these stem cells from becoming brain tumor stem cells that aid in the progression of GBM migration. ${ }^{4}$ No data were generated to study this effect; however, this may be considered in future trials.

\section{Defining the Appropriate Target}

In the field of radiation oncology, GTV (gross tumor volume), CTV (clinical tumor volume), and PTV (planning tumor volume) describe target volumes of tumor vis-à-vis obvious tumor, not obvious tumor, and mechanical/subjective error volumes. The CTV is usually considered to cover an added amount of "edge" to attempt to reach even cells that have migrated millimeters away from the GTV. The LE CTV would therefore include the entire FLAIR volume (even $4-5 \mathrm{~cm}$ away from the GTV) plus the GTV. The actual defined LE would therefore equal the CTV minus the GTV, as long as the CTV was defined as gadolinium-enhancing tumor volume plus the entire 3D FLAIR volume. In other words, CTV takes on a new definition for GBM.

Appropriate radiosurgical targeting is essential to the success of radiation therapy in treating GBM. It has become clear that targeting the contrast-enhancing portion of the tumor alone will be insufficient, even after a fractionated 3-cm margin during IFXRT (RTOG 93-0543).,12,32, 35,47 The tumor cells are well on their way down white matter pathways by that point. Thus, the critical target is the migratory pathway leading from the epicenter of tumor cell growth. We think that either FLAIR MRI sequences and/or MRI-SPECT sequences are best used to determine these theoretical pathways, which frequently include the corpus callosum. In most patients with GBM, the volumes of these abnormal regions were well within the $50-\mathrm{cm}^{3}$ range and could be safely targeted for stereotactic radiosurgery. In some cases, targets included FLAIR abnormalities that were $5 \mathrm{~cm}$ distant from the original enhancing nidus. White matter atlases based on study of GBM tumor cell-migration statistics may provide computer-modeling assistance in the future.

\section{Leading-Edge Calculation Algorithm}

To standardize a potentially subjective definition of the LE, a planning algorithm is proposed. Prior to the day of radiosurgery, 1.5- or 3.0-T MRI 2-mm-thick FLAIR will be performed on all patients' images. The FLAIR abnormality will be outlined and a target volume will be calculated of just this region. This is to exclude patients with tumor volumes greater than a proposed upper volume limit of $80 \mathrm{~cm}^{3}$. If the patient satisfies inclusion criteria on the day of LERS, a volume calculation will be performed. Doses will be administered to this target volume as follows: $0-20 \mathrm{~cm}^{3}, 10 \mathrm{~Gy} ; 21-40 \mathrm{~cm}^{3}, 9$ Gy; $41-60 \mathrm{~cm}^{3}, 8$ Gy; and $61-80 \mathrm{~cm}^{3}, 7 \mathrm{~Gy}$. In our experience, we think that these dose ranges have an acceptable safety profile.

\section{Radiosurgical Dose Selection}

Following typical dose-volume relationships, high volumes of tissue receive lower doses of stereotactic radio- surgery. Although the targeted LE tissue is presumed to contain migrating tumor cells, the appearance of the T1weighted MR sequences is much like normal brain. Thus, the median dose choice of $8 \mathrm{~Gy}$ at the $50 \%$ isodose line was predicated at delivering a maximum of 16 Gy to relatively normal-appearing brain tissue with "invisible" tumor cells. In this series, few patients had complications related to edema and only 7 (4\%) required surgery for debulking for symptomatic TRICs. One would not consider this to be a negative complication if it was at the expense of active tumor. Clearly, in more functional brain areas, the clinical risk must be considered. We believe that these low doses are sufficient to either scar the white matter pathways, limit local invasion and migration, and/or cause direct tumor cell death within them. Cells will undergo apoptosis if they are rendered unable to migrate..$^{12,37}$ Dose escalation or deescalation studies can be considered in the future.

Study limitations of single-user determination of the LE may be addressed using the LE calculation algorithm in a multicenter trial. In addition, diffusion tensor imaging, which was not used in this series, may prove helpful in delineating the extent of the LE. Although the molecular and genetic mutation data were average to unfavorable for survivability in this series, this information was available for only one-third of patients. Going forward, molecular and genetic analysis data will accompany all patients. Finally, selection of the patients for this study included those with tumors crossing midline as well as tumors involving the brainstem, thalamus, and cerebellum; such patients are often excluded in other studies.

\section{Conclusions}

LERS is a useful adjunct to standard therapy of GBM. Based on these data, very long survival times can be potentially achieved with its use. A multi-institution study will further clarify its role in the treatment of this elusive disease.

\section{References}

1. Abd-El-Barr MM, Chiocca EA: How much is enough? The question of extent of resection in glioblastoma multiforme. World Neurosurg 82:e109-e110, 2014

2. Beliën AT, Paganetti PA, Schwab ME: Membrane-type 1 matrix metalloprotease (MT1-MMP) enables invasive migration of glioma cells in central nervous system white matter. $\mathbf{J}$ Cell Biol 144:373-384, 1999

3. Bloch O, Han SJ, Cha S, Sun MZ, Aghi MK, McDermott $\mathrm{MW}$, et al: Impact of extent of resection for recurrent glioblastoma on overall survival: clinical article. J Neurosurg 117:1032-1038, 2012

4. Capilla-Gonzalez V, Bonsu JM, Redmond KJ, Garcia-Verdugo JM, Quiñones-Hinojosa A: Implications of irradiating the subventricular zone stem cell niche. Stem Cell Res (Amst) 16:387-396, 2016

5. Carter T, Shaw H, Cohn-Brown D, Chester K, Mulholland P: Ipilimumab and bevacizumab in glioblastoma. Clin Oncol (R Coll Radiol) [epub ahead of print], 2016

6. Coburger J, Hagel V, Wirtz CR, König R: Surgery for glioblastoma: impact of the combined use of 5-aminolevulinic acid and intraoperative MRI on extent of resection and survival. PLoS One 10:e0131872, 2015

7. Cohen MH, Shen YL, Keegan P, Pazdur R: FDA drug approval summary: bevacizumab (Avastin) as treatment of re- 
current glioblastoma multiforme. Oncologist 14:1131-1138, 2009

8. Dandy W: Removal of right cerebral hemisphere for certain tumors with hemiplegia. Preliminary report. JAMA 90:823825,1928

9. Demuth T, Berens ME: Molecular mechanisms of glioma cell migration and invasion. J Neurooncol 70:217-228, 2004

10. Feuer EJ, Rabin BA, Zou Z, Wang Z, Xiong X, Ellis JL, et al: The Surveillance, Epidemiology, and End Results Cancer Survival Calculator SEER*CSC: validation in a managed care setting. J Natl Cancer Inst Monogr 2014:265-274, 2014

11. Fonkem E, Wong ET: NovoTTF-100A: a new treatment modality for recurrent glioblastoma. Expert Rev Neurother 12:895-899, 2012

12. Giese A, Kluwe L, Laube B, Meissner H, Berens ME, Westphal M: Migration of human glioma cells on myelin. Neurosurgery 38:755-764, 1996

13. Gilbert MR, Dignam JJ, Armstrong TS, Wefel JS, Blumenthal DT, Vogelbaum MA, et al: A randomized trial of bevacizumab for newly diagnosed glioblastoma. N Engl J Med 370:699-708, 2014

14. Gutin PH, Iwamoto FM, Beal K, Mohile NA, Karimi S, Hou BL, et al: Safety and efficacy of bevacizumab with hypofractionated stereotactic irradiation for recurrent malignant gliomas. Int J Radiat Oncol Biol Phys 75:156-163, 2009

15. Gutin PH, Leibel SA, Wara WM, Choucair A, Levin VA, Philips TL, et al: Recurrent malignant gliomas: survival following interstitial brachytherapy with high-activity iodine-125 sources. J Neurosurg 67:864-873, 1987

16. Gutin PH, Prados MD, Phillips TL, Wara WM, Larson DA, Leibel SA, et al: External irradiation followed by an interstitial high activity iodine-125 implant "boost" in the initial treatment of malignant gliomas: NCOG study 6G-82-2. Int J Radiat Oncol Biol Phys 21:601-606, 1991

17. Hegedus B, Zách J, Czirók A, Lövey J, Vicsek T: Irradiation and Taxol treatment result in non-monotonous, dosedependent changes in the motility of glioblastoma cells. J Neurooncol 67:147-157, 2004

18. Hochberg FH, Pruitt A: Assumptions in the radiotherapy of glioblastoma. Neurology 30:907-911, 1980

19. Kathagen-Buhmann A, Schulte A, Weller J, Holz M, Herold-Mende C, Glass R, et al: Glycolysis and the pentose phosphate pathway are differentially associated with the dichotomous regulation of glioblastoma cell migration versus proliferation. Neuro Oncol 18:1219-1229, 2016

20. Kelly PJ, Daumas-Duport C, Kispert DB, Kall BA, Scheithauer BW, Illig JJ: Imaging-based stereotaxic serial biopsies in untreated intracranial glial neoplasms. J Neurosurg 66:865-874, 1987

21. Kong DS, Lee JI, Kim JH, Kim ST, Kim WS, Suh YL, et al: Phase II trial of low-dose continuous (metronomic) treatment of temozolomide for recurrent glioblastoma. Neuro Oncol 12:289-296, 2010

22. Lamy S, Ben Saad A, Zgheib A, Annabi B: Olive oil compounds inhibit the paracrine regulation of TNF- $\alpha$-induced endothelial cell migration through reduced glioblastoma cell cyclooxygenase-2 expression. J Nutr Biochem 27:136-145, 2016

23. Lefranc F, Brotchi J, Kiss R: Possible future issues in the treatment of glioblastomas: special emphasis on cell migration and the resistance of migrating glioblastoma cells to apoptosis. J Clin Oncol 23:2411-2422, 2005

24. Li Q, Cheng Q, Chen Z, Peng R, Chen R, Ma Z, et al: MicroRNA-663 inhibits the proliferation, migration and invasion of glioblastoma cells via targeting TGF- $\beta 1$. Oncol Rep 35:1125-1134, 2016

25. Li R, Li Y, Hu X, Lian H, Wang L, Fu H: Transcription factor 3 controls cell proliferation and migration in glioblastoma multiforme cell lines. Biochem Cell Biol 94:247-255, 2016
26. Li XZ, Li YB, Cao Y, Li PL, Liang B, Sun JD, et al: Prognostic implications of resection extent for patients with glioblastoma multiforme: a meta-analysis. J Neurosurg Sci [epub ahead of print], 2016

27. Li Y, Wei Z, Dong B, Lian Z, Xu Y: Silencing of phosphoglucose isomerase/autocrine motility factor decreases U87 human glioblastoma cell migration. Int J Mol Med 37:9981004,2016

28. Malkki H: Trial Watch: Glioblastoma vaccine therapy disappointment in Phase III trial. Nat Rev Neurol 12:190, 2016

29. Mokdad-Bzeouich I, Kovacic H, Ghedira K, Chebil L, Ghoul M, Chekir-Ghedira L, et al: Esculin and its oligomer fractions inhibit adhesion and migration of U87 glioblastoma cells and in vitro angiogenesis. Tumour Biol 37:3657-3664, 2016

30. Onken J, Torka R, Korsing S, Radke J, Krementeskaia I, Nieminen $\mathrm{M}$, et al: Inhibiting receptor tyrosine kinase AXL with small molecule inhibitor BMS-777607 reduces glioblastoma growth, migration, and invasion in vitro and in vivo. Oncotarget 7:9876-9889, 2016

31. Otvos B, Silver DJ, Mulkearns-Hubert EE, Alvarado AG, Turaga SM, Sorensen MD, et al: Cancer stem cell-secreted macrophage migration inhibitory factor stimulates myeloid derived suppressor cell function and facilitates glioblastoma immune evasion. Stem Cells 34:2026-2039, 2016

32. Pedersen PH, Edvardsen K, Garcia-Cabrera I, Mahesparan R, Thorsen J, Mathisen B, et al: Migratory patterns of lac-Z transfected human glioma cells in the rat brain. Int J Cancer 62:767-771, 1995

33. Perry JR, Rizek P, Cashman R, Morrison M, Morrison T: Temozolomide rechallenge in recurrent malignant glioma by using a continuous temozolomide schedule: the "rescue" approach. Cancer 113:2152-2157, 2008

34. Postow MA, Callahan MK, Barker CA, Yamada Y, Yuan J, Kitano S, et al: Immunologic correlates of the abscopal effect in a patient with melanoma. N Engl J Med 366:925-931, 2012

35. Price SJ, Jena R, Burnet NG, Carpenter TA, Pickard JD, Gillard JH: Predicting patterns of glioma recurrence using diffusion tensor imaging. Eur Radiol 17:1675-1684, 2007

36. Qiu Z, Yuan W, Chen T, Zhou C, Liu C, Huang Y, et al: HMGCR positively regulated the growth and migration of glioblastoma cells. Gene 576:22-27, 2016

37. Reardon DA, Rich JN, Friedman HS, Bigner DD: Recent advances in the treatment of malignant astrocytoma. J Clin Oncol 24:1253-1265, 2006

38. Richards L: Immunotherapy: a promising vaccine for glioblastoma multiforme. Nat Rev Clin Oncol 8:4, 2011

39. Rowther FB, Wei W, Dawson TP, Ashton K, Singh A, Madiesse-Timchou MP, et al: Cyclic nucleotide phosphodiesterase-1C (PDE1C) drives cell proliferation, migration and invasion in glioblastoma multiforme cells in vitro. Mol Carcinog 55:268-279, 2016

40. Sayegh ET, Oh T, Fakurnejad S, Bloch O, Parsa AT: Vaccine therapies for patients with glioblastoma. J Neurooncol 119:531-546, 2014

41. Schijns VE, Pretto C, Devillers L, Pierre D, Hofman FM, Chen TC, et al: First clinical results of a personalized immunotherapeutic vaccine against recurrent, incompletely resected, treatment-resistant glioblastoma multiforme (GBM) tumors, based on combined allo- and auto-immune tumor reactivity. Vaccine 33:2690-2696, 2015

42. Seliger C, Meyer AL, Renner K, Leidgens V, Moeckel S, Jachnik B, et al: Metformin inhibits proliferation and migration of glioblastoma cells independently of TGF- $\beta 2$. Cell Cycle 15:1755-1766, 2016

43. Souhami L, Seiferheld W, Brachman D, Podgorsak EB, Werner-Wasik M, Lustig R, et al: Randomized comparison of stereotactic radiosurgery followed by conventional radio- 
therapy with carmustine to conventional radiotherapy with carmustine for patients with glioblastoma multiforme: report of Radiation Therapy Oncology Group 93-05 protocol. Int J Radiat Oncol Biol Phys 60:853-860, 2004

44. Stamell EF, Wolchok JD, Gnjatic S, Lee NY, Brownell I: The abscopal effect associated with a systemic anti-melanoma immune response. Int J Radiat Oncol Biol Phys 85:293295, 2013

45. Stupp R, Hegi ME, Mason WP, van den Bent MJ, Taphoorn MJ, Janzer RC, et al: Effects of radiotherapy with concomitant and adjuvant temozolomide versus radiotherapy alone on survival in glioblastoma in a randomised phase III study: 5-year analysis of the EORTC-NCIC trial. Lancet Oncol 10:459-466, 2009

46. Stupp R, Mason WP, van den Bent MJ, Weller M, Fisher $\mathrm{B}$, Taphoorn MJ, et al: Radiotherapy plus concomitant and adjuvant temozolomide for glioblastoma. $\mathbf{N}$ Engl J Med 352:987-996, 2005

47. Talos IF, Zou KH, Kikinis R, Jolesz FA: Volumetric assessment of tumor infiltration of adjacent white matter based on anatomic MRI and diffusion tensor tractography. Acad Radiol 14:431-436, 2007

48. Tao H, Guo L, Chen L, Qiao G, Meng X, Xu B, et al: MSX1 inhibits cell migration and invasion through regulating the Wnt/ $\beta$-catenin pathway in glioblastoma. Tumour Biol 37:1097-1104, 2016

49. Thomas AA, Fisher JL, Ernstoff MS, Fadul CE: Vaccinebased immunotherapy for glioblastoma. CNS Oncol 2:331349, 2013

50. Tseliou M, Al-Qahtani A, Alarifi S, Alkahtani SH, Stournaras C, Sourvinos G: The role of RhoA, RhoB and RhoC GTPases in cell morphology, proliferation and migration in human cytomegalovirus (HCMV) infected glioblastoma cells. Cell Physiol Biochem 38:94-109, 2016

51. Vassallo I, Zinn P, Lai M, Rajakannu P, Hamou MF, Hegi ME: WIF1 re-expression in glioblastoma inhibits migration through attenuation of non-canonical WNT signaling by downregulating the lncRNA MALAT1. Oncogene 35:12-21, 2016

52. Vogelbaum MA: Does extent of resection of a glioblastoma matter? Clin Neurosurg 59:79-81, 2012

53. Wallner KE, Galicich JH, Krol G, Arbit E, Malkin MG: Patterns of failure following treatment for glioblastoma multiforme and anaplastic astrocytoma. Int J Radiat Oncol Biol Phys 16:1405-1409, 1989
54. Xiong W, Yin A, Mao X, Zhang W, Huang H, Zhang X: Resveratrol suppresses human glioblastoma cell migration and invasion via activation of RhoA/ROCK signaling pathway. Oncol Lett 11:484-490, 2016

55. Xu LW, Chow KK, Lim M, Li G: Current vaccine trials in glioblastoma: a review. J Immunol Res 2014:796856, 2014

56. Yan JL, van der Hoorn A, Larkin TJ, Boonzaier NR, Matys T, Price SJ: Extent of resection of peritumoral diffusion tensor imaging-detected abnormality as a predictor of survival in adult glioblastoma patients. J Neurosurg [epub ahead of print April 8, 2016. DOI: 10.3171/2016.1.JNS152153]

57. Zhang D, Li Y, Wang R, Li Y, Shi P, Kan Z, et al: Inhibition of REST suppresses proliferation and migration in glioblastoma cells. Int J Mol Sci 17:E664, 2016

58. Zhao HF, Wang J, Jiang HR, Chen ZP, To SS: PI3K p110 $\beta$ isoform synergizes with JNK in the regulation of glioblastoma cell proliferation and migration through Akt and FAK inhibition. J Exp Clin Cancer Res 35:78, 2016

\section{Disclosures}

The authors report no conflict of interest concerning the materials or methods used in this study or the findings specified in this paper.

\section{Author Contributions}

Conception and design: Duma. Acquisition of data: Duma, Kim, Chen, Plunkett, Mackintosh, Mathews, Casserly, Mendez, G Smith, Caraway, Sanathara, Weiland, Stemler, Cannell, BrantZawadzki. Analysis and interpretation of data: Duma, Plunkett, Mackintosh, Mathews, Weiland. Drafting the article: Duma, Chen, Mathews, Casserly, Mendez. Critically revising the article: Duma, Kim, Chen, Sanathara. Reviewed submitted version of manuscript: Duma, Plunkett, Casserly, Furman, Sanathara, Riley, Weiland, Stemler, Cannell, Abrams, A Smith, Owen. Approved the final version of the manuscript on behalf of all authors:

Duma. Administrative/technical/material support: Duma, Kim, Chen, Dillman, Eisenberg, Brant-Zawadzki. Study supervision: Duma, Dillman.

\section{Corresponding Author}

Christopher M. Duma, Brain Tumor and Gamma Knife Programs, Hoag Memorial Hospital Presbyterian, 3900 West Coast Hwy., Ste. 300, Newport Beach, CA 92663. email: cduma@mac.com. 